\title{
Extracellular DNA release confers heterogeneity in Candida albicans biofilm formation
}

\author{
Ranjith Rajendran', Leighann Sherry', David F Lappin', Chris J Nile', Karen Smith², Craig Williams², \\ Carol A Munro ${ }^{3}$ and Gordon Ramage ${ }^{1 *}$
}

\begin{abstract}
Background: Biofilm formation by Candida albicans has shown to be highly variable and is directly associated with pathogenicity and poor clinical outcomes in patients at risk. The aim of this study was to test the hypotheses that the extracellular DNA release by C. albicans is strain dependent and is associated with biofilm heterogeneity.

Results: Initially, biofilm formed by C. albicans high biofilm formers (HBF) or low biofilm formers (LBF) were treated with DNase to find whether eDNA play a role in their biofilm formation. Digestion of biofilm eDNA significantly reduced the HBF biofilm biomass by five fold compared to untreated controls. In addition, quantification of eDNA over the period of biofilm formation by SYBR green assay demonstrate a significantly higher level of 2 to 6 fold in HBF compared to LBF. Biochemical and transcriptional analyses showed that chitinase activity and mRNA levels of chitinase genes, a marker of autolysis, were upregulated in $24 \mathrm{~h}$ biofilm formation by HBF compared to LBF, indicating autolysis pathway possibly involved in causing variation. The biofilm biomass and eDNA release by single $(\Delta c h t 2, \Delta c h t 3)$ and double knockout $(\Delta c h t 2 / \Delta c h t 3)$ chitinase mutants were significantly less compared to their parental strain CA14, confirming the role of chitinases in eDNA release and biofilm formation. Correlation analysis found a positive correlation between chitinases and HWP1, suggesting eDNA may release during the hyphal growth. Finally, we showed a combinational treatment of biofilms with DNase or chitinase inhibitor (acetazolamide) plus amphotericin B significantly improved antifungal susceptibility by 2 to 8 fold.
\end{abstract}

Conclusions: Collectively, these data show that eDNA release by C. albicans clinical isolates is variable and is associated with differential biofilm formation. Digestion of biofilm eDNA by DNase may provide a novel therapeutic strategies to destabilise biofilm growth and improves antifungal sensitivity.

Keywords: Candida albicans, Biofilm, eDNA, Chitinases

\section{Background}

Candida albicans is a dimorphic fungal pathogen that causes both superficial and systemic candidiasis [1]. Invasive systemic forms of the disease affect at-risk patients and can lead to mortality rates as high as $63 \%$ in some instances [2]. The disease is multifactorial [3], yet the capacity of $C$. albicans to form biofilms has been identified as a pivotal factor to patient outcomes $[4,5]$. These structures are found frequently associated with indwelling medical devices, as well as biological surfaces such as the mucosa [6], and are clinically important due

\footnotetext{
* Correspondence: gordon.ramage@glasgow.ac.uk

'Infection and Immunity Research Group, Glasgow Dental School, School of Medicine, College of Medical, Veterinary and Life Sciences, University of Glasgow, 378 Sauchiehall Street, Glasgow G2 3JZ, UK

Full list of author information is available at the end of the article
}

to their high recalcitrance to antifungal treatment [7]. However, there is increasing evidence in the literature that C. albicans biofilm formation is heterogeneous, which has a direct impact upon treatment and pathogenicity [4,8-10]. Studies have indicated that depending on the ability to form a biofilm, or not, has a bearing on patient outcomes, though the conclusions from some of these studies are diametrically opposed $[4,9]$. Therefore, rather than defining biofilm formation as an absolute parameter we have recently described a series of clinical isolates with a differential ability to form biofilms, in which high biofilm forming (HBF) isolates displayed a greater pathogenic capacity and lower antifungal sensitivity when compared to low biofilm forming (LBF) isolates [10]. However, the mechanisms underlying the difference in biofilm formation are not yet fully understood. 
Extracellular matrix (ECM) is an important and defining characteristic of biofilms, providing a structural scaffold whilst coincidentally facilitating protection from external factors, including antifungal agents $[7,11]$. Typical fungal biofilm ECM is a heterogeneous substance consisting of exopolysaccharides, proteins, surfactants, lipids and water [12,13], though recent studies have shown the presence of another important component extracellular DNA in fungal biofilm matrix [13,14]. These studies demonstrated that eDNA plays a significant role with respect to structural stability and as a consequence antifungal sensitivity. In both $C$. albicans and $A$. fumigatus it was shown that addition of exogenous DNA significantly improved biofilm formation, and that depletion of biofilm eDNA through the addition of DNase adversely affects the biomass [13,14]. It can be inferred from bacterial biofilm studies that eDNA has a multifactorial purpose, namely as a nutrient source [15], facilitator of genetic information exchange [16], contributor to biofilm stability and dispersal [17-20], and as an antimicrobial resistance factor [21,22]. The mechanism of eDNA release in biofilm environment is not yet fully understood, though studies in bacterial species suggests various mechanisms that are potentially responsible for this process, including cell lysis [23,24]. We recently demonstrated the association of the chitinase regulated autolytic pathway with eDNA release in $A$. fumigatus [14], however, chitinase activity in C. albicans biofilms with respect to eDNA has yet to be studied. Given that eDNA contributes to ECM integrity, and ECM is a key factor in promoting biofilm formation, we hypothesised that the capacity to release eDNA through differential chitinase activity may be an underlying mechanism supporting biofilm heterogeneity.

\section{Methods}

\section{Isolates and maintenance}

C. albicans SC5314 and a series of routine patient anonymised clinical bloodstream isolates $(n=6)$ were collected under the approval of the NHS Scotland Caldicott Gaurdians from the Royal Hospital for Sick Children (Yorkhill Division), Glasgow, UK, as part of candidaemia epidemiology surveillance study were used throughout this study. Furthermore, chitinase mutants $\Delta c h t 2, \Delta c h t 3, \Delta c h t 2 / \Delta c h t 3$, including the parental strain CA14 were also used. Isolates were stored on Sabouraud dextrose agar (Oxoid, Basingstoke, UK) at $4^{\circ} \mathrm{C}$. All C. albicans strains were grown on YPD at $37^{\circ} \mathrm{C}$ overnight. Cells were then washed and resuspended in appropriate media to the desired concentration, as described previously [25]. All procedures were carried out in a laminar flow cabinet (Hera Safe laminate flow cabinet, Kendro, model K515).

\section{Assessment of biofilm formation}

The growth rate of the clinical isolates was first assessed. Each isolate was standardised to $1 \times 10^{4}$ cells $/ \mathrm{mL}$ in YPD dispensed into each well of a 96 well round-bottom plate and incubated at $37^{\circ} \mathrm{C}$ for $24 \mathrm{~h}$. The absorbance was measured at $530 \mathrm{~nm}$ every $1 \mathrm{~h}$ in a microtitre plate reader (FluoStar Omega, BMG Labtech). Each isolate was tested in duplicate and repeated on three independent occasions. Negative controls containing no C. albicans were included for background correction. For biofilm screening isolates were processed as described previously [10]. Biofilms were then grown in a 96 well flat-bottomed polystyrene plate (Corning Incorporated, NY, USA) at $37^{\circ} \mathrm{C}$ for $24 \mathrm{~h}$ as described previously [25]. Following incubation, biofilms were carefully washed twice with PBS to remove any nonadherent cells and biomass of each isolate assessed using a crystal violet assay (CV) [26]. Air dried biofilms were stained with $0.05 \% \mathrm{w} / \mathrm{v}$ CV for $20 \mathrm{~min}$, washed to remove excess stain, then destained with $100 \%$ ethanol. This was transferred to a new 96 well plate and absorbance was read at $570 \mathrm{~nm}$. Isolates with CV absorbance of $\geq 1.5$ were classified as high biofilm former ( $\mathrm{HBF}$ ) and $\leq 0.5$ were classified as low biofilm former (LBF), as previously described [10].

\section{Effect of DNase treatment on preformed biofilms}

The role of eDNA in C. albicans biofilm formation was first investigated by depletion of eDNA within the biofilm using a hydrolytic enzyme DNase I. DNase I from bovine pancreas (Sigma-Aldrich) was prepared in $0.15 \mathrm{M} \mathrm{NaCl}$ supplemented with $5 \mathrm{mM}$ of $\mathrm{MgCl}_{2}$. Biofilms of $\operatorname{HBF}(n=3)$ and $\operatorname{LBF}(n=3)$ isolates were grown in RPMI-1640 as described above. Following incubation, biofilms were washed with PBS and treated with $256 \mu \mathrm{g} / \mathrm{mL}$ of DNase (Sigma-Aldrich) for $24 \mathrm{~h}$ at $37^{\circ} \mathrm{C}$, a concentration previously shown to decrease fungal biofilm biomass [14,27]. Untreated controls were also included for direct comparison. Biofilms were then washed twice with PBS and the biomass was scraped from the surface and passed through $0.22 \mu \mathrm{M}$ membrane filters. Biofilms retained on the filters were dried overnight at $60^{\circ} \mathrm{C}$ and then dry weight measurements were taken for each isolate, as described previously [28]. Measurement of each isolate was carried out in duplicate, on three independent occasions.

\section{Assessment of extracellular DNA release}

C. albicans isolates with $\operatorname{LBF}(\mathrm{n}=3), \operatorname{HBF}(\mathrm{n}=3), \mathrm{CA} 14$, and chitinase mutants $\Delta c h t 2, \Delta c h t 3$ and $\Delta c h t 2 / \Delta c h t 3$ biofilms were grown in RPMI-1640 for 4 and $24 \mathrm{~h}$ at $37^{\circ} \mathrm{C}$. The quantity of eDNA release was measured using a microplate fluorescence assay (MFA) using a DNA binding dye $\left(\mathrm{SYBR}^{\oplus}\right.$ Green I), as previously described [14]. Briefly, $\mathrm{SYBR}^{\oplus}$ Green I (Invitrogen) was added to biofilm supernatants in a black well microtitre plate (Costar3603; 
Corning) at a ratio of 1:4. Binding of this dye produces fluorescence directly proportional to DNA concentration. The levels of eDNA were quantified using a fluorescence plate reader (Fluostar Optima; BMG Labtech) at 485 and $518 \mathrm{~nm}$, respectively. The concentration of eDNA in the sample was quantified using the DNA standard curve as previously described [29]. In addition, optical density of the culture was measured at $530 \mathrm{~nm}$ simultaneously for normalising the relative fluorescence units (RFU) data. Each isolate was tested in duplicate, on three separate occasions.

\section{Fluorescence microscopy}

Standardised C. albicans $\left(1 \times 10^{6}\right.$ cells $\left./ \mathrm{ml}\right)$ were inoculated in RPMI medium onto Thermanox ${ }^{\mathrm{TM}}$ coverslips $(13 \mathrm{~mm})$ within a 24 -well tissue culture plate, then incubated for $24 \mathrm{~h}$ at $37^{\circ} \mathrm{C}$. These were gently rinsed with PBS and stained according to the manufacturers' instructions with $5 \mu \mathrm{M}$ calcofluor white (Invitrogen), which binds chitin and beta-glucans of fungal cell walls, and with $20 \mu \mathrm{M}$ propidium iodide (PI) (Sigma), which stains the DNA present within a biofilm. Biofilm growth and accumulation of eDNA were visualized under a fluorescence microscope (Motic BA400 Colorview system) at $\mathrm{Ex}_{350} / \mathrm{Em}_{400}$ for calcofluor white, and $\mathrm{Ex}_{540} / \mathrm{Em}_{525}$ for propidium iodide. Representative images from 10 fields were taken and one from each group was digitally photographed.

\section{Quantifying chitinase activity}

C. albicans chitinase activity was quantified from isolates with $\operatorname{LBF}(\mathrm{n}=3)$ and $\operatorname{HBF}(\mathrm{n}=3)$ after 4 and 24 h of biofilm formation using a fluorometric chitinase assay kit (Sigma, United Kingdom), as per the manufacturer's instructions. Following biofilm development, supernatants were collected at 4 and $24 \mathrm{~h}$, and an appropriate volume of each sample was incubated with a substrate working solution (4-methylumbelliferyl $\mathrm{N}$-acetyl- $\beta$-d-glucosaminide) at $37^{\circ} \mathrm{C}$ for $30 \mathrm{~min}$. Fluorescence was then quantified at $\mathrm{Ex}_{360} / \mathrm{Em}_{450}$. Appropriate positive and negative controls included in the kit were added to each plate. Chitinase activity was calculated and expressed as a ratio between chitinase units and optical density of culture (U/OD). Each isolate was measured in duplicate, on three separate occasions.

\section{Quantitative gene expression}

C. albicans $\operatorname{HBF}(n=3)$ and $\operatorname{LBF}(n=3)$ biofilms were prepared in 24 well polystyrene plates as described above for 4 and $24 \mathrm{~h}$ at $37^{\circ} \mathrm{C}$. Quantitative analysis of transcriptional changes within these biofilms was performed as previously described [30]. Briefly, RNA was extracted by mechanical disruption in TRIzol (Invitrogen) and purified using an RNeasy MinElute cleanup kit (Qiagen, Crawley, United Kingdom) as per the manufacturer's instructions. RNA was quantified and its quality determined using a NanoDrop spectrophotometer (ND-1000; Thermo Scientific, Loughborough, United Kingdom). Then, cDNA was synthesised with a high-capacity RNA-to-cDNA master mix (Applied Biosystems), using a MyCycler PCR machine (Bio-Rad, Hertfordshire, United Kingdom), and was stored at $-20^{\circ} \mathrm{C}$ for expression analysis. The expression of the chitinase genes CHT2 and CHT3 and markers of hyphal cell growth and adhesion (HWP1 and ALS3) were then assessed using quantitative reverse transcription-PCR (RT-PCR) with SYBR ${ }^{\oplus}$ GreenER $^{\mathrm{Tm}}$ (Invitrogen), according to the manufacturer's instructions. Primer sequences for these genes are shown in Table 1. The individual gene expression levels were then calculated using the $2^{-\Delta C T}$ method for different phases and normalized to the ACT1 housekeeping gene. All isolates were tested in duplicate for this experiment.

\section{Scanning electron microscopy}

C. albicans single ( $\Delta$ cht $2, \Delta$ cht 3$)$, double knockout $(\Delta c h t 2 / \Delta c h t 3)$ chitinase mutants and their parental strain CA14 were standardised and grown as biofilm in RPMI-1640 directly onto Thermanox ${ }^{\mathrm{TM}}$ coverslips (Nunc, Roskilde, Denmark) for $24 \mathrm{~h}$. Following biofilm development, biofilms were carefully washed with PBS before fixation in $2 \%$ para-formaldehyde, $2 \%$ gluteraldehyde and $0.15 \mathrm{M}$ sodium cacodylate, and $0.15 \% \mathrm{w} / \mathrm{v}$ Alcian Blue, $\mathrm{pH} 7.4$, and prepared for scanning electron microscopy (SEM), as previously described [31]. The samples were sputter-coated with gold and viewed under a JEOL JSM6400 SEM. Images were assembled using Photoshop software (Adobe, San Jose, CA, USA) at magnification $\times 1000$.

\section{Biofilm susceptibility testing in the presence of DNase and azetazolamide}

The impact of eDNA and chitinases on amphotericin B sensitivity was assessed using a hydrolytic enzyme DNase I and a chitinase inhibitor acetazolamide ([AZE] Sigma-Aldrich). C. albicans LBF $(\mathrm{n}=3), \operatorname{HBF}(\mathrm{n}=3)$ and SC5314 were standardized to $1 \times 10^{6}$ cells $/ \mathrm{ml}$ in RPMI-

\section{Table 1 C. albicans primers used for qPCR}

\begin{tabular}{|c|c|c|}
\hline Gene & Sequence $\left(5^{\prime}-3^{\prime}\right)$ & Function \\
\hline \multirow[t]{2}{*}{$A L S 3$} & F - CAACTTGGGTTATTGAAACAAAAACA & Adhesin \\
\hline & R - AGAAACAGAAACCCAAGAACAACCT & \\
\hline \multirow[t]{2}{*}{ HWP1 } & F - GCTCAACTTATTGCTATCGCTTATTACA & Hyphal wall protein \\
\hline & R - GACCGTCTACCTGTGGGACAGT & \\
\hline \multirow[t]{2}{*}{ CHT2 } & F - TGATTTATTATCCAAAGTCCCACTTG & Chitinase \\
\hline & R - TTGAATTGGCCATTGATTGAA & \\
\hline \multirow[t]{2}{*}{ CHT3 } & F - TGCTACTATTCCAGATGACAAAGAAATT & Chitinase \\
\hline & R - TTCAGTGATGATAGCAGGTGGTTT & \\
\hline \multirow[t]{2}{*}{$A C T 1$} & F - AAGAATTGATTTGGCTGGTAGAGA & Actin - housekeeping \\
\hline & R - TGGCAGAAGATTGAGAAGAAGTTT & \\
\hline
\end{tabular}


1640 and biofilms grown in flat bottomed 96 well plates for 4 and $24 \mathrm{~h}$. Preformed biofilms were washed twice with $\mathrm{PBS}$ and treated with serially diluted $\mathrm{AMB} \pm$ DNase $(256 \mu \mathrm{g} / \mathrm{ml})$ or \pm AZE $(256 \mu \mathrm{g} / \mathrm{ml})$. The concentrations of DNase and AZE were previously shown to be effectively disrupting the biomass and improve antifungal sensitivity [14,27]. Biofilms were incubated for a further $24 \mathrm{~h}$ at $37^{\circ} \mathrm{C}$ before metabolic activity assessed using the XTT assay, as described previously [32].

\section{Statistics}

Analysis of variance (ANOVA) and t-tests were used to investigate independent sample data. A Bonferroni correction for multiple comparisons was applied to the data where appropriate. SPSS (Version 11, Chicago, USA) was used for these analysis and GraphPad Prism (Version 4, La Jolla, USA) for the production of the figures. The Spearman's rho correlation coefficient was determined to investigate the relationship between the parameters measured. A $p$ value of less than 0.05 was considered significant.

\section{Results}

Candida albicans eDNA release is correlated with biofilm formation and promotes antifungal resistance Initially, we assessed C. albicans biofilm formation by six bloodstream isolates defined as either low biofilm former (LBF, $\mathrm{n}=3$ ) or high biofilm former $(\mathrm{HBF}, \mathrm{n}=3$ ) based on biomass quantification. A significant difference in biofilm formation was observed between isolates with LBF and HBF, where $11.6 \times$ more $(\mathrm{p}=0.0035)$ biomass was observed in the latter group (Figure 1A). We then evaluated whether the presence of eDNA contributed to C. albicans biofilms formation. To do so we investigated how each LBF and HBF isolate responded to DNase treatment. A significant biomass (dry weight) reduction was observed for the HBF $(\mathrm{p}<0.01)$, with a 5 -fold decrease in biomass compared to untreated controls (Figure 1B). In comparison, isolates with the LBF phenotype did not show any significant biomass reduction. To further investigate the hypothesis that eDNA preferentially supported biofilm growth, we evaluated its release from both HBF and LBF at 4 and $24 \mathrm{~h}$ using SYBR green I assay. eDNA release was significantly greater in isolates with $\mathrm{HBF}$ compared to LBF at both $4 \mathrm{~h}$ and $(2.78$ fold, $\mathrm{p}<0.05)$ and $24 \mathrm{~h}$ (5.89 fold, $\mathrm{p}<0.01$ ) (Figure $1 \mathrm{C}$ ). Moreover, eDNA release increased significantly by a further 2.79 fold $(\mathrm{p}=$ 0.0221 ) in HBF isolates between 4 and $24 \mathrm{~h}$. No differences in growth rates were observed between the 6 test isolates (Additional file 1: Figure S1).

Next, the impact of eDNA on AMB sensitivity was then tested to determine its role in antifungal resistance. It was shown that isolates with LBF were up to 8-fold

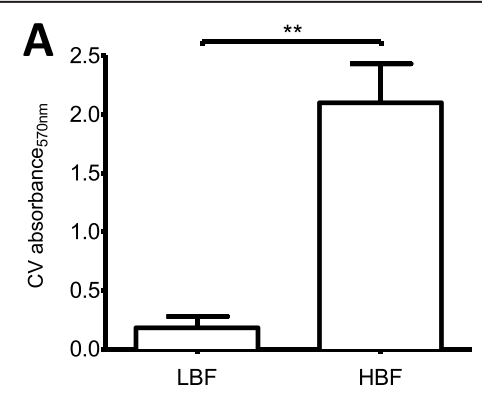

C

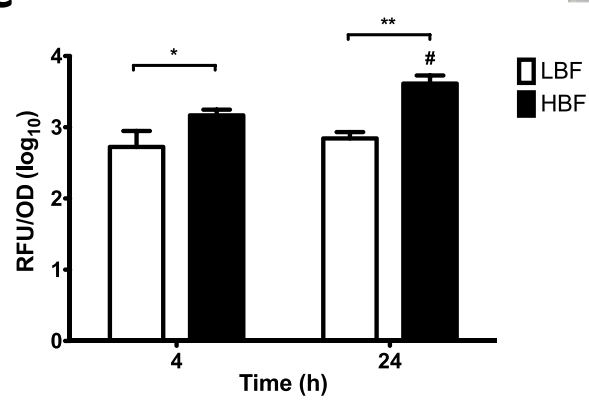

Figure 1 Variation in C. albicans biofilm formation and eDNA release. C. albicans isolates with $L B F(n=3)$ and $H B F(n=3)$ were grown as biofilms in 96 well flat-bottom microtitre plates at $37^{\circ} \mathrm{C}$ for $24 \mathrm{~h}$. (A) Biofilm biomass was assessed spectrophotometrically by reading CV absorbance, data represents mean \pm SD. (B) Biofilms were treated $\pm 256 \mu \mathrm{g} / \mathrm{ml}$ DNase for a further $24 \mathrm{~h}$ before being passed through $0.22 \mu \mathrm{M}$ membrane filter. Biomass retained on the filters was dried overnight at $60^{\circ} \mathrm{C}$ and dry weight measurements taken. In addition, biofilms were stained with $\mathrm{CV}$ and imaged to show the disruptive effect of DNase on the biofilms, data represents mean \pm SE. (C) Isolates were grown as biofilms for 4 and $24 \mathrm{~h}$ in the presence of the DNA binding dye SYBR ${ }^{\oplus}$ Green I. Fluorescence was measured after 4 and $24 \mathrm{~h}$ at Ex485/Em518. Absorbance was measured simultaneously for normalising the fluorescence data, data represents mean \pm SD. Each isolate was tested in duplicate, on three independent occasions. ${ }^{* *} p<0.05,{ }^{* *} p<0.01$. 
Table 2 MIC of amphotericin B against C. albicans SC5314, LBF and HBF

Minimum inhibitory concentrations (MICs)

\begin{tabular}{|c|c|c|c|c|c|c|}
\hline \multirow[t]{2}{*}{ Strain } & \multicolumn{3}{|l|}{$4 \mathrm{~h}$ biofilm } & \multicolumn{3}{|l|}{24 h biofilm } \\
\hline & $\begin{array}{l}\text { AMB MIC } \\
(\mathrm{mg} / \mathrm{L})\end{array}$ & $\begin{array}{l}\mathrm{FC}^{* *}+ \\
\mathrm{DNase}\end{array}$ & $\begin{array}{l}\text { FC+ } \\
\text { AZE }\end{array}$ & $\begin{array}{l}\text { AMB MIC } \text { MI } \\
(\mathrm{mg} / \mathrm{L})\end{array}$ & $\begin{array}{l}\mathrm{FC}+ \\
\text { DNase }\end{array}$ & $\begin{array}{l}\text { FC+ } \\
\text { AZE }\end{array}$ \\
\hline SC5314 & $<0.0313$ & 1 & 1 & 0.5 & 4 & 2 \\
\hline LBF & 0.0313 & 1 & 1 & $0.25-0.5$ & $1-2$ & 1 \\
\hline $\mathrm{HBF}$ & $0.125-0.25$ & $1-2$ & 1 & $0.25-1$ & $4-8$ & 2 \\
\hline
\end{tabular}

${ }^{*} \mathrm{MIC}_{50}-$ Minimum concentration of AMB at which $50 \%$ reduction in viability assessed by XTT assay.

**FC - Fold change in MIC of AMB in the presence and absence of DNase or acetazolamide (AZE).

more susceptible to $\mathrm{AMB}$ than those with $\mathrm{HBF}$ at $4 \mathrm{~h}$. However, when comparing these biofilm subsets at $24 \mathrm{~h}$ there was only a 2-fold difference in MIC (Table 2). The addition of DNase during AMB treatment did not have an impact on isolates with LBF at $4 \mathrm{~h}$, with only a 2 -fold difference observed at $24 \mathrm{~h}$ with DNase treatment. In contrast, isolates with $\mathrm{HBF}$ were most susceptible to $\mathrm{AMB}+\mathrm{DNase}$ therapy at both time points, particularly $24 \mathrm{~h}$ where up to 8 -fold decrease in MIC were observed in the presence of DNase. The addition of DNase with AMB increased AMB sensitivity by up to 2 and 8 -fold in HBF isolates from 4 and $24 \mathrm{~h}$ biofilms, respectively, whereas, those LBF isolates showed no change at $4 \mathrm{~h}$, and only a 2 fold change at $24 \mathrm{~h}$ (Table 2 ).

\section{Differential expression of Candida albicans chitinase activity} is correlated with eDNA release and biofilm formation

Based on previous work from our group, which showed a positive correlation between chitinase activity in Aspergillus fumigatus biofilms and eDNA release [14], we decided to evaluate whether this property was also observed in $C$. albicans biofilms. Although no differences in chitinase activity were identified with biochemical assay between LBF and HBF isolates at $4 \mathrm{~h}$, a significant change of $\sim 3$-fold greater activity detected at $24 \mathrm{~h}(\mathrm{p}<0.05)$ with $\mathrm{HBF}$ compared to LBF (Figure 2A). Furthermore, transcriptional analysis found no difference in CHT2 expression at $4 \mathrm{~h}$ between the two biofilm subsets, a significant up-regulation by $23 \%(\mathrm{p}<0.05)$ was observed at $24 \mathrm{~h}$ in those with HBF compared to those with LBF (Figure 2B). In addition, despite $\mathrm{CHT} 3$ expression being increased by 4 -fold and 3-fold in isolates with HBF than LBF at 4 and $24 \mathrm{~h}$, respectively, no significant difference between the groups was observed (Figure 2C). In addition, the expression of biofilm-related genes HWP1 and ALS3 in C. albicans biofilms was evaluated and it was found that these were up-regulated in isolates with HBF. Despite ALS3 and HWP1 expression being increased in HBF by $11 \times(\mathrm{p}=0.1143)$ and $18 \times(\mathrm{p}=0.1447)$
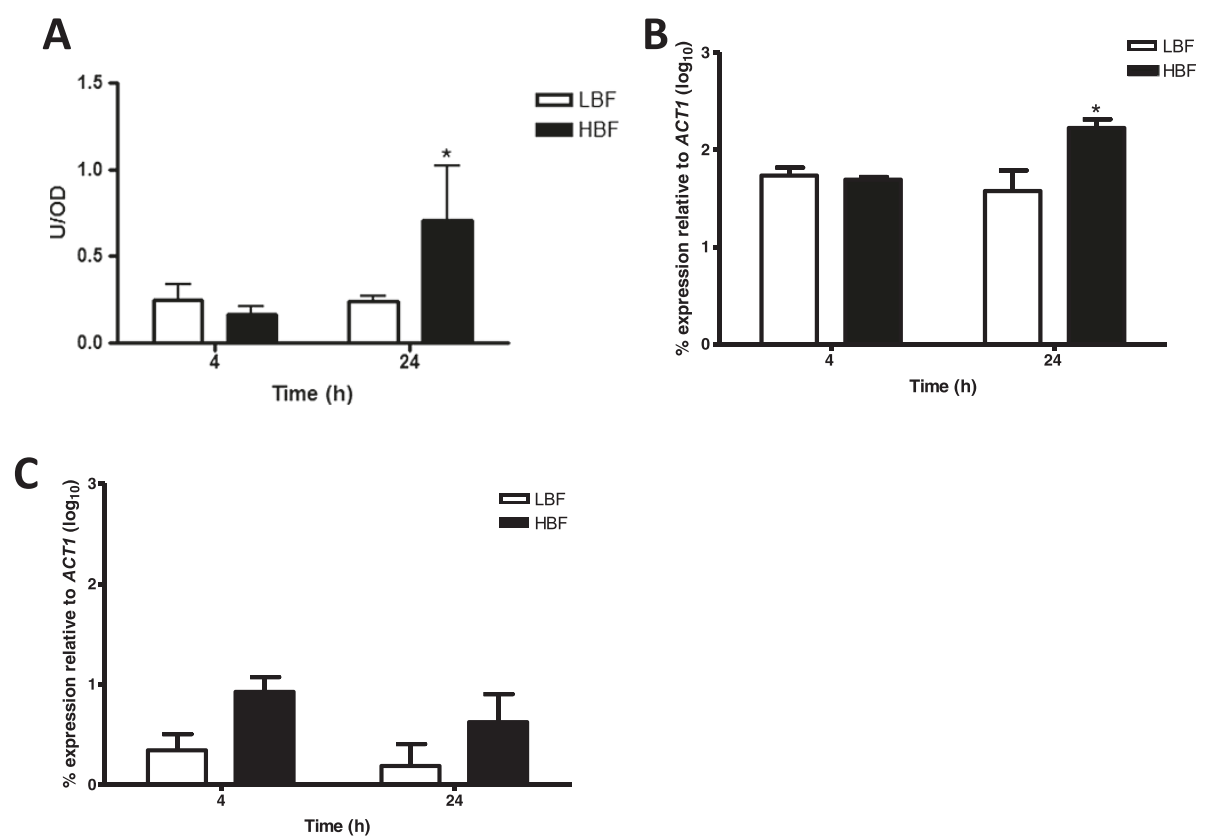

Figure 2 Chitinases play a role in C. albicans biofilm formation. Three C. albicans isolates with LBF and HBF were standardised to $1 \times 10^{6}$ cells/ml in RPMl-1640 and grown in 24 well microtitre plates at $37^{\circ} \mathrm{C}$ for 4 and $24 \mathrm{~h}$. (A) Supernatants were retained and mixed with a chitinase substrate working solution for $30 \mathrm{~min}$ at $37^{\circ} \mathrm{C}$. Fluorescence was measured at 360 and $450 \mathrm{~nm}$ and chitinase activity represented at $\mathrm{U} / \mathrm{OD}$, normalised to isolate biomass. Each isolate was measured in duplicate, on three separate occasions. (B-C) Biofilms with LBF $(n=3)$ and HBF $(n=3)$ were washed with PBS and RNA extracted using the TRIzol method, cDNA synthesised and real-time PCR used to measure the expression of CHT2 (B) and CHT3 (C). Percentage of gene expression is shown as $\log _{10}$ mean \pm SD relative to housekeeping gene $A C T 1 .{ }^{*} \mathrm{p}<0.05$. 
at $4 \mathrm{~h}$ (Figure 3A) when compared to LBF respectively, the only significant difference in the transcriptional analysis was observed at $24 \mathrm{~h}$ where LBF had $18 \times$ less expression of $A L S 3(\mathrm{p}=0.0102)$ than HBF (Figure 3B).

To investigate the relationship between eDNA release, chitinase activity, biofilm biomass and genes related to biofilm formation (HWP1 and ALS3), a Spearman's rho correlation analysis was performed (Table 3). A significant correlation was observed between eDNA release and biomass $(\mathrm{p}<0.01)$, chitinase activity $(\mathrm{p}<0.01)$, and expression of HWP1 $(\mathrm{p}<0.05)$ and ALS3 $(\mathrm{p}<0.05)$ at $24 \mathrm{~h}$. A significant positive correlation was also found between chitinase activity and expression of HWP1 $(\mathrm{p}<0.05)$ in 24 h biofilms (Table 3 ).

Compromising Candida albicans chitinase activity affects isolates biofilm formation and antifungal sensitivity

C. albicans single and double knockout mutants $\Delta$ cht2, $\Delta c h t 3$ and $\Delta$ cht $2 / \Delta c h t 3$ were assessed to confirm whether these chitinases played a role in eDNA release and biofilm formation. These all showed a reduction in
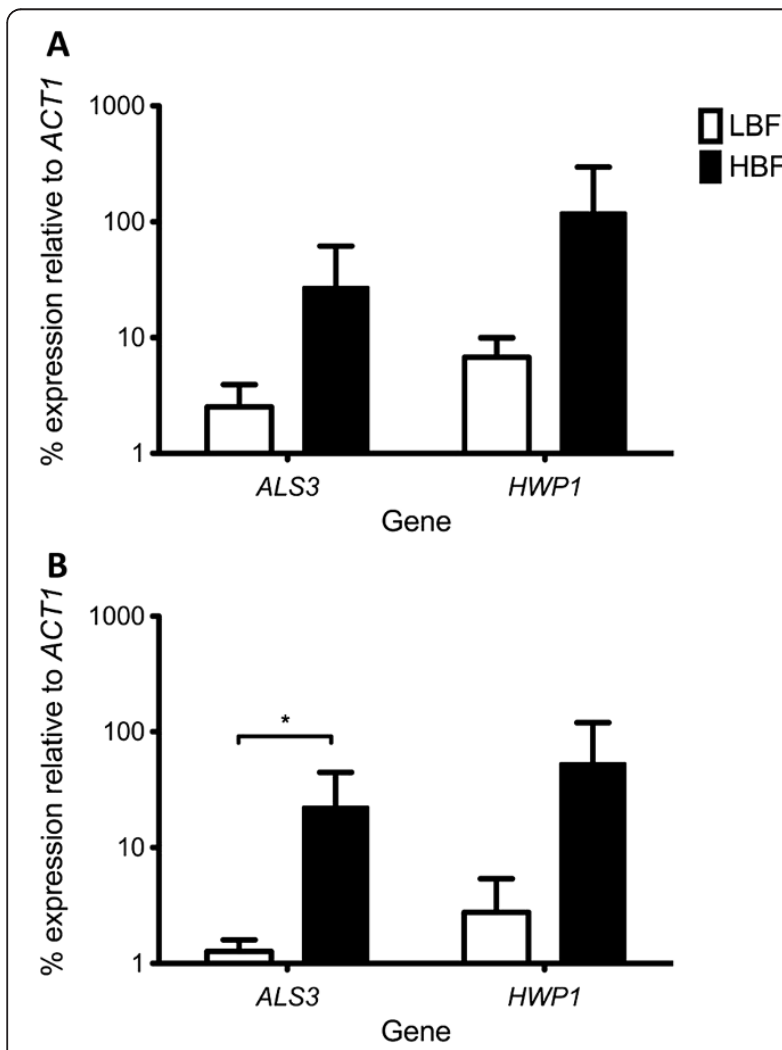

Figure 3 Expression of biofilm related genes is up-regulated in C. albicans isolates with HBF. Biofilms with LBF $(n=3)$ and HBF $(n=3)$ were grown for $4(\mathbf{A})$ and $24 \mathrm{~h}(\mathbf{B})$ before RNA extracted, CDNA synthesised and qPCR used to measure the expression of ALS3 and HWP1. Each individual isolate was measured in duplicate. Percentage of gene expression is represented by mean \pm SD relative to housekeeping gene ACT1. ${ }^{*} p<0.05$.
Table 3 Spearman's rho correlation analysis

\begin{tabular}{llcccc}
\hline Spearman's rho & Biomass & Chitinase & HWP1 & ALS3 \\
\hline eDNA & Correlation Coefficient & $.829^{*}$ & $.771^{*}$ & $.886^{* *}$ & $.829^{*}$ \\
& Sig. & .021 & .036 & .009 & .021 \\
\multirow{2}{*}{ Chitinase } & Correlation Coefficient & $.771^{*}$ & & $.771^{*}$ & .600 \\
& Sig. & .036 & & .036 & .104 \\
\hline
\end{tabular}

${ }^{*}$ Correlation is significant at the 0.05 level.

${ }^{* *}$ Correlation is significant at the 0.01 level.

biofilm biomass when compared to their parental strain CA14. However, a significant reduction was found only with $\Delta c h t 3(\mathrm{p}<0.05)$ and $\Delta c h t 2 / \Delta c h t 3(\mathrm{p}<$ 0.005 ) (Figure 4A). To investigate whether this reduction in biomass is caused by presence of eDNA, the biofilms were treated with DNase. Here a significant reduction in biofilm biomass by 2 -fold was observed with DNase treatment in CA14 compared to untreated controls $(\mathrm{p}<0.01)$. Conversely, no significant reduction was observed with either single or double knockout mutants (Figure 4A). The reduction in biofilm formation by all the knockout mutants was confirmed by microscopy (Figure 4B). SEM imaging showed reduced biomass in these isolates compared to CA14, with $\Delta c h t 3$ showing the clearest visual difference, providing evidence that chitinases plays a role in C. albicans biofilm formation. eDNA release was also quantified in these mutants. All knockout strains had significantly reduced eDNA release after $24 \mathrm{~h}$. The greatest reduction was in $\Delta c h t 2$, where a significant eDNA reduction of $53 \%(\mathrm{p}<$ $0.05)$ was measured compared to the wild-type, followed by $\Delta$ cht $2 / \Delta$ cht 3 with reduction of $50 \%(\mathrm{p}=0.0061)$, and $\Delta c h t 3$ where eDNA release was reduced by $26 \%(\mathrm{p}=$ 0.0161 ) (Figure $4 \mathrm{C}$ ). The level of eDNA present in these knockout mutants was confirmed visually using fluorescence imaging. The presence of eDNA in the parental strain CA14 is shown by the abundance of red/pink fluorescence, which was notably reduced in the single knockouts $\Delta$ cht 2 and $\Delta c h t 3$, and completely absent from the double knockout $\Delta c h t 2 / \Delta c h t 3$ (Figure 4D).

Finally, to test whether pharmacological inhibition of chitinases impacted antifungal sensitivity, AZE was used in combination with $\mathrm{AMB}$. It was shown that the addition of AZE did not alter AMB sensitivity in any of the LBF biofilms at $4 \mathrm{~h}$ and $24 \mathrm{~h}$. However, isolates with HBF had up to a 2 fold decrease in $\mathrm{MIC}_{50}$ at both 4 and $24 \mathrm{~h}$ (Table 2).

\section{Discussion}

Our group have recently described that biofilms formed by different clinical isolates of $C$. albicans are heterogeneous. Significant variation in their ability to form and maintain biofilm structure exists between bloodstream isolates, which was shown not only to impact biofilm formation, but also pathogenicity and antifungal sensitivity 
B
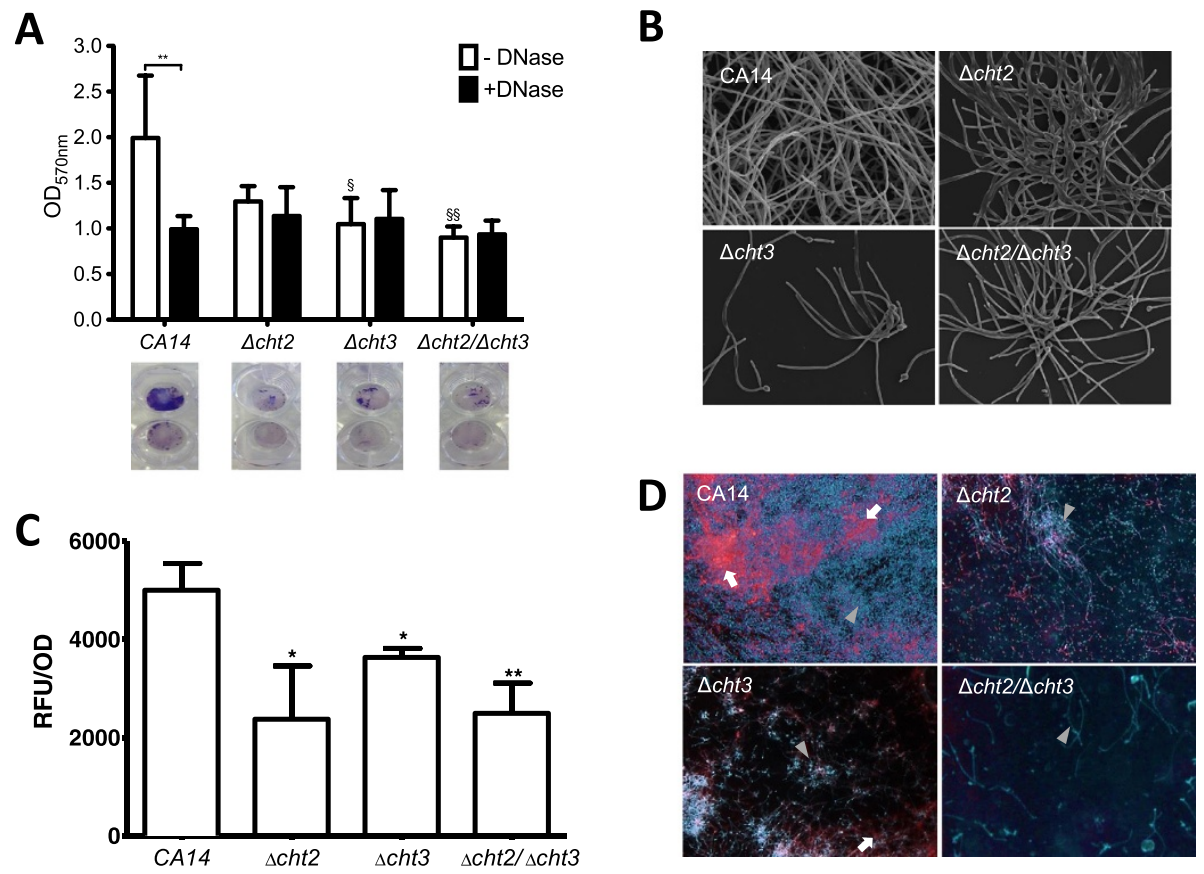

Figure 4 Compromising chitinase activity decreases eDNA release and biofilm formation in C. albicans. C. albicans $\Delta c h t 2, \Delta c h t 3, \Delta c h t 2 /$ $\Delta c h t 3$ and parental strain CA14 biofilms were grown in 96 well microtitre plates for $24 \mathrm{~h}$ at $37^{\circ} \mathrm{C}$ in RPMl (A) Following biofilm development, biofilms were carefully washed with PBS and incubated in RPMI for a further $24 \mathrm{~h}, \pm 256 \mu \mathrm{g} / \mathrm{ml}$ DNase. Biomass assessed spectrophotometrically by measuring CV absorbance at $570 \mathrm{~nm}$. Also CV stained biofilms were digitally imaged to show the difference in biofilm formation and effect of DNase treatment. $\S P<0.05, \S \S p<0.01$. (B) C. albicans $\Delta c h t 2, \Delta c h t 3, \Delta c h t 2 / \Delta c h t 3$ and wild type CA14 $(\times 1000)$ were grown on Thermanox ${ }^{T M}$ coverslips for $24 \mathrm{~h}$ at $37^{\circ} \mathrm{C}$. Biofilms were then processed and viewed on a JEOL JSM-6400 scanning electron microscope and images assembled using Photoshop software. Note the reduction in biofilm biomass in $\Delta c h t 3$ and $\Delta c h t 2 / \Delta c h t 3$. (C) eDNA release was measured after 4 and $24 \mathrm{~h}$ using SYBR green I assay, normalised to each isolates biomass. Each isolate was measured in duplicate, on three separate occasions. ${ }^{*} p<0.05$, ${ }^{* *} \mathrm{p}<0.01$. (D) Biofilm growth (hyphal cells indicated by arrow head) and accumulation of eDNA (Indicated by arrow) were visualized under a fluorescence microscope (Motic BA400 Colorview system) at an Ex/Em wavelengths of 350/400 nm for calcofluor white and 540/525 nm for propidium iodide. One representative from each group was digitally photographed.

[10]. Understanding why these isolates differ would be useful in developing better management strategies, both in terms of antifungal therapy, but potentially also for development of new molecular diagnostics. The data presented herein describes a novel role for eDNA release in conferring heterogeneity during biofilm formation by C. albicans, which is associated with chitinase regulated autolytic events, and which contributes to biofilm associated antifungal resistance.

There have been limited studies to date examining the presence and role of eDNA in C. albicans biofilms $[13,27,33]$. These studies demonstrate that the quantity of eDNA in biofilms varied considerably with the growth medium used, with RPMI showing a significantly higher accumulation of eDNA in ECM compared to other tested media [13]. We reported that RPMI consistently supports optimal biofilm formation for C. albicans [10]. Given that eDNA was associated with high levels of biofilm formation it was hypothesised that this may explain the underlying mechanism for the heterogeneity, i.e. those isolates with the propensity to form biofilms may release more eDNA than isolates forming structurally simple biofilms. This is supported by the data showing that addition of exogenous DNA has been shown to significantly improve biofilm biomass [14,34]. Moreover, there are studies highlighting the importance of eDNA within mixed C. albicans and bacterial biofilms [33,35]. To test these hypotheses two groups of contrasting biofilm forming abilities were investigated. Based on two biomass quantification assays the isolates were categorised as LBF and HBF, from which eDNA release was initially evaluated. Here the levels of eDNA observed were greater in isolates with HBF, which also increased with biofilm maturity, which is a similar finding to that reported in studies of A. fumigatus biofilm development [14].

The release of eDNA in fungal biofilms is hypothesised to be an end product of autolysis, a process controlled by various hydrolases, including chitinases [14,36]. C. albicans have also been shown to possess complex chitinase families that hydrolyse chitin molecules in fungal cell wall [37]. These enzymes are known to be involved in spore formation, hyphal growth, hyphal branching and septum formation. There are four chitinase genes known in C. albicans (CHT1-4), though their function remains unclear. CHT2 
and $C H T 3$ have been shown to be associated with yeast to hyphal morphogenesis and are more active in the hyphal form [38]. Here it was reported that these enzymes were transcriptionally expressed and biochemically active during the release of eDNA, which in turn contributes towards biofilm formation. Indeed, correlation analysis demonstrates the functional relationship between eDNA release, chitinase activity and biofilm formation. Furthermore, a positive correlation between chitinase activity and a hyphal cell marker HWP1 suggest the involvement of chitinases in hyphal growth, which in turn contributes to eDNA release. This may explain the morphological differences between the HBF and LBF, of which the former demonstrates more filamentous growth [10]. It was also shown that compromising chitinase activity through gene deletion of $\Delta \operatorname{cht} 2, \Delta \operatorname{cht} 3$ and $\Delta \operatorname{cht} 2 / \Delta \operatorname{cht} 3$ significantly affects eDNA release and biofilm formation, which suggests a role for chitinases in the maintenance and architecture of $C$. albicans biofilms.

From a translational perspective, the mechanism of eDNA release could represent an Achilles heal in the management of tenacious HBF isolates. eDNA release was shown to improve AMB resistance, demonstrated through DNase combinational treatments and also through pharmacological inhibition of chitinases that may regulate eDNA release. Collectively, these data demonstrate the possibility of improving our treatment of these infections through rationally designed strategies. Mismanagement also has important repercussions, as it has been shown that treatment with sub-MIC levels of antifungals causes an increase in chitin content within Candida species, which relates to decreased antifungal sensitivity $[39,40]$. Moreover, a recent study has shown the use of sub-lethal concentrations of antibiotics leads to increased autolysis, eDNA release and biofilm formation in bacteria [41]. Tumbarello and colleagues identified inadequate antifungal therapy as a predictor of patient mortality [42], with other studies highlighting the importance of efficient and appropriate treatment of candidaemia cases [43,44]. Therefore, careful consideration must be given with regards to antifungal use as ineffectual therapy can lead to increased antifungal resistance and increased hospital lengths of stay.

\section{Conclusions}

The data from this study showed a variation in biofilm formation among C. albicans isolates and how it affects the antifungal sensitivity. Strain dependent eDNA release and chitinase activity is associated with biofilm formation. Finally, pharmacological inhibition of eDNA by DNase or AZE reduced biofilm resistance to AMB in C. albicans. Thus, we establish a potential mechanism regulating biofilm heterogeneity and antifungal resistance, and that targeting eDNA may provide an effective strategy for management of biofilm based infections.

\section{Additional file}

Additional file 1: Figure S1. Variation in Candida albicans biofilm formation is independent of growth kinetics. The growth kinetics of C. albicans isolates with LBF (grey circle) and HBF (black square) was assessed over $24 \mathrm{~h}$, with absorbance read at $530 \mathrm{~nm}$ every hour. Isolates with LBF $(n=3)$ and HBF $(n=3)$ were grown in duplicate, on three separate occasions. Data represents mean value.

\section{Abbreviations}

ACT: Actin; CHT: Chitinase; ALS: Aglutanin like sequence; AMB: Amphotericin B; ANOVA: Analysis of variance; AZE: Acetazolamide; CV: Crystal violet; ECM: Extracellular matrix; eDNA: Extracellular DNA; Em: Emission;

Ex: Excitation; HBF: High biofilm former; HWP: Hyphal wall protein; LBF: Low biofilm former; MIC: Minimum inhibitory concentration; PBS: Phosphate buffered saline; qPCR: Quantitative polymerase chain reaction; RFU: Relative fluorescence units; RPMI: Roswell park memorial institute; SD: Standard deviation; SE: Standard error of the mean; SEM: Scanning electron microscopy; U/OD: Chitinase units per optical density; XTT: 2,3-bis(2methoxy-4-nitro-5-sulfo-phenyl)-2H-tetrazolium-5-caboxanilide; YPD: Yeast peptone dextrose.

\section{Competing interests}

The authors declare that they have no competing interests.

\section{Authors' contributions}

RR and LS participated in the study design, carried out the experimental studies, performed statistical analysis and were responsible for the manuscript. DFL and CJN participated in study design, assisted with statistical support and helped draft the manuscript. CW contributed to study design and supervised manuscript writing. KS participated in qPCR analysis and manuscript writing. CAM participated in study design and analysis. GR conceived the study, participated in study design, data analysis and was responsible for writing and submission of the final manuscript. All authors read and approved the manuscript.

\section{Acknowledgements}

Margaret Mullin (University of Glasgow) for her assistance in scanning electron microscopy techniques.

\section{Author details}

${ }^{1}$ Infection and Immunity Research Group, Glasgow Dental School, School of Medicine, College of Medical, Veterinary and Life Sciences, University of Glasgow, 378 Sauchiehall Street, Glasgow G2 3JZ, UK. ' Institute of Healthcare Associated Infection, School of Health, Nursing and Midwifery, University of the West of Scotland, Paisley, UK. ${ }^{3}$ Aberdeen Fungal Group, Institute of Medical Sciences, Foresterhill, University of Aberdeen, Aberdeen AB25 2ZD, UK.

Received: 15 July 2014 Accepted: 19 November 2014

Published online: 05 December 2014

\section{References}

1. Odds FC: Candida infections: an overview. Crit Rev Microbiol 1987, 15(1):1-5

2. Kollef M, Micek S, Hampton N, Doherty JA, Kumar A: Septic shock attributed to Candida infection: importance of empiric therapy and source control. Clin Infect Dis 2012, 54(12):1739-1746.

3. Eggimann $\mathrm{P}$, Bille J, Marchetti $\mathrm{O}$ : Diagnosis of invasive candidiasis in the ICU. Ann Intensive Care 2011, 1:37

4. Tumbarello M, Fiori B, Trecarichi EM, Posteraro P, Losito AR, De Luca A, Sanguinetti M, Fadda G, Cauda R, Posteraro B: Risk factors and outcomes of candidemia caused by biofilm-forming isolates in a tertiary care hospital. PLoS One 2012, 7(3):e33705.

5. Andes DR, Safdar N, Baddley JW, Playford G, Reboli AC, Rex JH, Sobel JD, Pappas PG, Kullberg BJ: Impact of treatment strategy on outcomes in patients with candidemia and other forms of invasive candidiasis: a patient-level quantitative review of randomized trials. Clin Infect Dis 2012, 54(8):1110-1122

6. Ramage G, Williams C: The clinical importance of fungal biofilms. Adv Appl Microbiol 2013, 84:27-83 
7. Ramage G, Rajendran R, Sherry L, Williams C: Fungal biofilm resistance. Int J Microbiol 2012, 2012:528521.

8. Alnuaimi AD, O'Brien-Simpson NM, Reynolds EC, McCullough MJ: Clinical isolates and laboratory reference Candida species and strains have varying abilities to form biofilms. FEMS Yeast Res 2013, 13(7):689-699.

9. Guembe M, Guinea J, Marcos-Zambrano L, Fernandez-Cruz A, Pelaez T, Munoz $P$, Bouza E: Is biofilm production a predictor of catheter-related candidemia? Med Mycol 2014, 52(4):407-410.

10. Sherry L, Rajendran R, Lappin DF, Borghi E, Perdoni F, Falleni M, Tosi D, Smith K, Williams C, Jones B, Nile CJ, Ramage G: Biofilms formed by Candida albicans bloodstream isolates display phenotypic and transcriptional heterogeneity that are associated with resistance and pathogenicity. BMC Microbiol 2014, 14(1):182.

11. Flemming HC, Wingender J: The biofilm matrix. Nat Rev Microbiol 2010, 8(9):623-633.

12. Al-Fattani MA, Douglas LJ: Biofilm matrix of Candida albicans and Candida tropicalis: chemical composition and role in drug resistance. J Med Microbiol 2006, 55(Pt 8):999-1008.

13. Martins M, Uppuluri P, Thomas DP, Cleary IA, Henriques M, Lopez-Ribot JL, Oliveira R: Presence of extracellular DNA in the Candida albicans biofilm matrix and its contribution to biofilms. Mycopathologia 2010, 169(5):323-331.

14. Rajendran R, Williams C, Lappin DF, Millington O, Martins M, Ramage G: Extracellular DNA release acts as an antifungal resistance mechanism in mature Aspergillus fumigatus biofilms. Eukaryot Cell 2013, 12(3):420-429.

15. Mulcahy $\mathrm{H}$, Charron-Mazenod L, Lewenza S: Pseudomonas aeruginosa produces an extracellular deoxyribonuclease that is required for utilization of DNA as a nutrient source. Environ Microbiol 2010, 12(6):1621-1629.

16. Molin S, Tolker-Nielsen T: Gene transfer occurs with enhanced efficiency in biofilms and induces enhanced stabilisation of the biofilm structure. Curr Opin Biotechnol 2003, 14(3):255-261.

17. Whitchurch CB, Tolker-Nielsen T, Ragas PC, Mattick JS: Extracellular DNA required for bacterial biofilm formation. Science 2002, 295(5559):1487.

18. Izano EA, Amarante MA, Kher WB, Kaplan JB: Differential roles of poly-Nacetylglucosamine surface polysaccharide and extracellular DNA in Staphylococcus aureus and Staphylococcus epidermidis biofilms. Appl Environ Microbiol 2008, 74(2):470-476.

19. Conover MS, Mishra M, Deora R: Extracellular DNA is essential for maintaining Bordetella biofilm integrity on abiotic surfaces and in the upper respiratory tract of mice. PLoS One 2011, 6(2):e16861.

20. Berne C, Kysela DT, Brun W: A bacterial extracellular DNA inhibits settling of motile progeny cells within a biofilm. Mol Microbiol 2010, 77(4):815-829.

21. Mulcahy $\mathrm{H}$, Charron-Mazenod L, Lewenza S: Extracellular DNA chelates cations and induces antibiotic resistance in Pseudomonas aeruginosa biofilms. PLoS Pathog 2008, 4(11):e1000213.

22. Tetz GV, Artemenko NK, Tetz W: Effect of DNase and antibiotics on biofilm characteristics. Antimicrob Agents Chemother 2009, 53(3):1204-1209.

23. Allesen-Holm M, Barken KB, Yang L, Klausen M, Webb JS, Kjelleberg S, Molin $S$, Givskov M, Tolker-Nielsen T: A characterization of DNA release in Pseudomonas aeruginosa cultures and biofilms. Mol Microbiol 2006, 59(4):1114-1128.

24. Qin Z, Ou Y, Yang L, Zhu Y, Tolker-Nielsen T, Molin S, Qu D: Role of autolysin-mediated DNA release in biofilm formation of Staphylococcus epidermidis. Microbiology 2007, 153(Pt 7):2083-2092.

25. Ramage G, Vande Walle K, Wickes BL, Lopez-Ribot JL: Standardized method for in vitro antifungal susceptibility testing of Candida albicans biofilms. Antimicrob Agents Chemother 2001, 45(9):2475-2479.

26. Mowat E, Butcher J, Lang S, Williams C, Ramage G: Development of a simple model for studying the effects of antifungal agents on multicellular communities of Aspergillus fumigatus. J Med Microbiol 2007, 56(Pt 9):1205-1212.

27. Martins M, Henriques M, Lopez-Ribot JL, Oliveira R: Addition of DNase improves the in vitro activity of antifungal drugs against Candida albicans biofilms. Mycoses 2012, 55(1):80-85.

28. Richard ML, Nobile CJ, Bruno VM, Mitchell AP: Candida albicans biofilmdefective mutants. Eukaryot Cell 2005, 4(8):1493-1502.

29. Leggate J, Allain R, Isaac L, Blais BW: Microplate fluorescence assay for the quantification of double stranded DNA using SYBR Green I dye. Biotechnol Lett 2006, 28(19):1587-1594.

30. Ramage G, Coco B, Sherry L, Bagg J, Lappin DF: In vitro Candida albicans biofilm induced proteinase activity and SAP8 expression correlates with in vivo denture stomatitis severity. Mycopathologia 2012, 174(1):11-19.
31. Erlandsen SL, Kristich CJ, Dunny GM, Wells CL: High-resolution visualization of the microbial glycocalyx with low-voltage scanning electron microscopy: dependence on cationic dyes. J Histochem Cytochem 2004, 52(11):1427-1435.

32. Pierce CG, Uppuluri P, Tristan AR, Wormley FL Jr, Mowat E, Ramage G, Lopez-Ribot JL: A simple and reproducible 96-well plate-based method for the formation of fungal biofilms and its application to antifungal susceptibility testing. Nat Protoc 2008, 3(9):1494-1500.

33. Sapaar B, Nur A, Hirota K, Yumoto H, Murakami K, Amoh T, Matsuo T, Ichikawa T, Miyake Y: Effects of extracellular DNA from Candida albicans and pneumonia-related pathogens on Candida biofilm formation and hyphal transformation. J Appl Microbiol 2014, 116(6):1531-1542.

34. Shopova I, Bruns S, Thywissen A, Kniemeyer O, Brakhage AA, Hillmann F: Extrinsic extracellular DNA leads to biofilm formation and colocalizes with matrix polysaccharides in the human pathogenic fungus Aspergillus fumigatus. Front Microbiol 2013, 4:141.

35. Pammi M, Liang R, Hicks J, Mistretta TA, Versalovic J: Biofilm extracellular DNA enhances mixed species biofilms of Staphylococcus epidermidis and Candida albicans. BMC Microbiol 2013, 13:257.

36. White $S$, Mclntyre M, Berry DR, McNeil B: The autolysis of industrial filamentous fungi. Crit Rev Biotechnol 2002, 22(1):1-14.

37. Gooday GW, Wei-Yun Z, O'Donnell RW: What are the roles of chitinases in the growing fungus? FEMS Microbiol Lett 1992, 100(1-3):387-391.

38. Selvaggini S, Munro CA, Paschoud S, Sanglard D, Gow NA: Independent regulation of chitin synthase and chitinase activity in Candida albicans and Saccharomyces cerevisiae. Microbiology 2004, 150(Pt 4):921-928.

39. Walker LA, Gow NA, Munro CA: Elevated chitin content reduces the susceptibility of Candida species to caspofungin. Antimicrob Agents Chemother 2013, 57(1):146-154

40. Walker LA, Munro CA, de Bruijn I, Lenardon MD, McKinnon A, Gow NA Stimulation of chitin synthesis rescues Candida albicans from echinocandins. PLOS Pathog 2008, 4(4):e1000040.

41. Hsu CY, Lin MH, Chen CC, Chien SC, Cheng YH, Su IN, Shu JC: Vancomycin promotes the bacterial autolysis, release of extracellular DNA, and biofilm formation in vancomycin-non-susceptible Staphylococcus aureus. FEMS Immunol Med Microbiol 2011, 63(2):236-247.

42. Tumbarello M, Posteraro B, Trecarichi EM, Fiori B, Rossi M, Porta R, de Gaetano DK, La Sorda M, Spanu T, Fadda G, Cauda R, Sanguinetti M: Biofilm production by Candida species and inadequate antifungal therapy as predictors of mortality for patients with candidemia. J Clin Microbiol 2007, 45(6):1843-1850

43. Almirante B, Rodriguez D, Park BJ, Cuenca-Estrella M, Planes AM, Almela M, Mensa J, Sanchez F, Ayats J, Gimenez M, Saballs P, Fridkin SK, Morgan J, Rodriguez-Tudela JL, Warnock DW, Pahissa A: Epidemiology and predictors of mortality in cases of Candida bloodstream infection: results from population-based surveillance, barcelona, Spain, from 2002 to 2003. J Clin Microbiol 2005, 43(4):1829-1835.

44. Garey KW, Rege M, Pai MP, Mingo DE, Suda KJ, Turpin RS, Bearden DT: Time to initiation of fluconazole therapy impacts mortality in patients with candidemia: a multi-institutional study. Clin Infect Dis 2006, 43(1):25-31.

doi:10.1186/s12866-014-0303-6

Cite this article as: Rajendran et al.: Extracellular DNA release confers heterogeneity in Candida albicans biofilm formation. BMC Microbiology 2014 14:303.

\section{Submit your next manuscript to BioMed Central and take full advantage of:}

- Convenient online submission

- Thorough peer review

- No space constraints or color figure charges

- Immediate publication on acceptance

- Inclusion in PubMed, CAS, Scopus and Google Scholar

- Research which is freely available for redistribution 